\title{
La dramaturgia, piedra basal del Centro Andaluz de Teatro (1997-2004)
}

Entrevista a Emilio Hernández

\section{Miguel F. Gil Palacios}

\section{(2) OpenEdition}

\section{Journals}

Edición electrónica

URL: https://journals.openedition.org/cher/1040

DOI: $10.4000 /$ cher. 1040

ISSN: 2803-5992

\section{Editor}

Presses universitaires de Strasbourg

\section{Edición impresa}

Fecha de publicación: 11 julio 2019

Paginación: 21-25

ISBN: 979-10-344-0046-1

ISSN: 1968-035X

\section{Referencia electrónica}

Miguel F. Gil Palacios, «La dramaturgia, piedra basal del Centro Andaluz de Teatro (1997-2004)», reCHERches [En línea], 22 | 2019, Publicado el 04 octubre 2021, consultado el 19 noviembre 2021 URL: http://journals.openedition.org/cher/1040 ; DOI: https://doi.org/10.4000/cher.1040 


\title{
La dramaturgia, piedra basal del Centro Andaluz de Teatro (1997-2004) Entrevista a Emilio Hernández
}

\author{
Miguel F. GIL Palacios'
}

\begin{abstract}
G milio Hernández (Morón, Cuba, 1948) es dramaturgo, dramaturgista, - director de escena y gestor cultural. Ejerciendo este último oficio, fue Adjunto a la Dirección del Centro Dramático Nacional (1978-81), Coordinador de Programación del Teatro Español de Madrid (1982-83), Director del Centro Cultural de la Villa de Madrid (1988-89), Director del Centro Andaluz de Teatro (CAT) entre 1997 y 2004, Miembro Directivo de la Convención Teatral Europea entre 1998 y 2004, y Director del Festival de Almagro entre 2004 y 2010.

En la época en la que dirigió el CAT, la dramaturgia andaluza conoció un esplendor nunca visto. Se potenció a los autores ya establecidos, especialmente a los pertenecientes a la generación de Antonio Álamo, Juan García Larrondo y Antonio Onetti. Se trabajó en la identificación y la formación de los jóvenes dramaturgos y dramaturgas, y gracias a esto la Generación Romero Esteo logró consolidarse. Se investigó con ahínco sobre los autores andaluces del Renacimiento para revitalizar una parte importantísima de nuestro patrimonio que, eclipsada por la grandeza de nuestro teatro barroco, se encuentra prácticamente olvidada y completamente fuera de la escena.

Con objeto de desvelar la plaza que ocupaba la dramaturgia en su estrategia para el desarrollo del teatro andaluz, realizamos esta entrevista en Córdoba, el 13 de febrero de 2018.
\end{abstract}

Miguel F. Gil Palacios: Emilio, tú llegaste al CAT a finales de los 90, pero antes ya habías participado en la gestión de otras estructuras culturales, ¿puedes hablarme un poco de esto?

1 Miguel F. Gil Palacios, Departamento de Escritura y Ciencias Teatrales- Escuela Superior de Arte Dramático de Córdoba, España. 
Emilio Hernández: Yo venía de varias experiencias en distintos teatros públicos de Madrid. Estuve en la creación del Centro Dramático Nacional, en el equipo de Adolfo Marsillach, lo que fue un gran impulso para la escena española. Entonces no veíamos la dimensión, pero era el primer gran teatro público que se creaba en la democracia; y allí estuve, en el primer envite. Luego, pasé al Teatro Español, y más tarde dirigí el Centro Cultural de la Villa de Madrid, que entonces no producía, pero yo lo hice producir, y ahí arrancamos precisamente con un autor andaluz, Rafael Alberti, con aquella extraña obra: El hombre deshabitado.

Y bueno, la verdad es que poco a poco iba comprendiendo la necesidad de la cultura y el teatro en esta reciente democracia; que la cultura es algo imprescindible para levantar un país, pero que también es muy importante en el sentido económico, es decir, que estábamos ante una fuerza económica importante, ante un motor de movilización de las poblaciones en toda España.

Por otro lado, muy pronto me di cuenta de que un teatro público tenía que ser capaz de levantar una dramaturgia propia, que tenía que procurar que la gente joven pudiera empezar a poner en los escenarios sus textos, y tuviera el apoyo de los fondos del Estado para eso, tanto en el teatro contemporáneo como en el teatro clásico. El teatro clásico todavía en aquella época era algo que ahuyentaba a los espectadores, y el teatro muy contemporáneo también, a excepción de una pequeña minoría. Piensa que en Madrid estaba triunfando Tábano, que hacía Castañuela 70, que era una crítica del poder, una ironía sobre la situación de ese momento. Eso fue en la Transición, a caballo entre la dictadura y la democracia, pero los nuevos textos, los nuevos autores, estaban todavía un poco olvidados y temidos; y me parecía que era uno de los motores que había que poner en marcha. El Teatro Público tenía que apoyar a los nuevos creadores, a los nuevos autores, a los nuevos actores, a los nuevos directores...

Esa visión de la cultura y el teatro fue calando en mí cada vez más, y cuando me ofrecieron la dirección del CAT, lo vi como un apasionante reto, pues iba a poder hacer realidad lo que yo entonces estaba empezando a concebir sobre lo que tenía que ser un teatro público.

M.F.G.P.: Y entonces llegaste a Andalucía, pero tú ya habías tenido una experiencia previa en esta tierra, ¿no es así?

E. H.: Sí, ya estuve en Andalucía haciendo teatro en 1967, en plena dictadura. Se organizaban entonces desde el régimen franquista unas campañas universitarias de culturización por pueblos de diferentes regiones, el SUT (Servicio Universitario del Trabajo), y en este caso era en la provincia de Almería. Aunque el programa estaba controlado por algunos sindicatos verticales, algunos grupos más o menos sospechosos nos colamos por allí. Así llegamos hasta Almería con una furgona y recorrimos los pueblos montando en cada placita espectáculos con textos a los que les habíamos cambiado el nombre para que pudieran colar y representarse, porque eran textos de Brecht, poemas de Blas de Otero... Íbamos haciéndolos en las plazas de los pueblos, a pleno sol, viviendo en donde nos podía alojar la gente del pueblo y comiendo lo que buenamente nos daban. El problema venía cuando 
se filtraba de lo que iba el espectáculo y las fuerzas vivas de la localidad -iglesia y guardia civil- procuraban que nos echaran de allí. Tuvimos que salir huyendo de varios pueblos solo por eso. Esto fue el verano del 67, y ahí comencé a conocer yo Andalucía y a los andaluces, porque realmente había gente buena, emocionada, en las sillas de madera que poníamos en la placita debajo de un árbol. Gente que lloraba viendo nuestro trabajo y decía: "Eso es lo que pasa en mi pueblo", "Eso es lo que pasa aquí"; y apenas podían decirlo en voz alta.

M. F. G. P.: Y 30 años después, en 1997, vienes para dirigir el CAT. ¿Cómo fueron los primeros pasos de tu gestión?

E. H.: Yo me instalé en Andalucía en la primavera del 97. Primero empecé a conocer quién estaba, y quién dirigía y quién escribía. Empecé a ver a directores malditos, que no dirigían en el CAT, y gente que estaba un poco fuera. Lo primero que hice fue intentar colaborar con el equipo que había y con los actores que habían trabajado allí hasta entonces.

En lo referente a la dramaturgia, es verdad que una generación de autores estaba de alguna manera fuera de los estrenos oficiales. Despertar el interés por los nuevos autores fue un impulso para el que tuve muchos apoyos por parte de los compañeros. Lo hicimos a través del Premio Romero Esteo, con una promesa y una realidad clara, y es que los que escribiesen y obtuvieran ese premio iban a ser representados, cosa que no era habitual en la mayoría de los premios. Empezamos con lecturas dramáticas y seguimos muy pronto con representaciones y, bueno, tiramos de prensa, tiramos de todos los medios para que aquello realmente se conociera, no solo eso, sino que además, por mis contactos en Gran Bretaña, nos conectamos enseguida con una escuela muy importante, la Royal Court, contacté con sus directores, con Elyse Dogson, que estaba al frente de la sección internacional, para que, por un lado, los autores que estaban trabajando allí vinieran para participar en la formación de los nuevos autores andaluces, y por otro, para que cada año pudiera ir un autor andaluz a la Royal Court a trabajar allí. Eso fue inmediato, Vinieron Sara Kane, David Craig, Roy Williams..., autores que luego han sido dioses de la dramaturgia británica. Estuvieron en varios sitios, en Jaén, en Sevilla... trabajando, y efectivamente, apoyando la creación de la nueva dramaturgia andaluza.

Intentamos por encima de todo, aunque con pocos medios, que el teatro público andaluz fuera verdaderamente público, que sirviera para eso. Y todo esto se mantuvo entre mi llegada en 1997 y 2004, año en que terminó mi gestión al frente del CAT.

M.F.G.P.: También se apoyó mucho a la generación anterior a la "Romero Esteo", la de Antonio Onetti y Antonio Álamo.

E.H.: Sin duda, el CAT los apoyó, produjo las obras más maduras que tenían. Mi primera puesta en escena con el CAT fue precisamente una obra con Onetti, Madre caballo, una versión de Madre coraje de Brecht, nada más empezar, y eso ya enganchó con el público de una manera tan evidente, que efectivamente, 
comprobamos que era una generación que tenía mucho que decirle a la gente. Aquello fue un gran éxito que recorrió los escenarios españoles durante años.

M.F. G.P.: Resulta sorprendente la importancia que le das a la dramaturgia en el marco de tu gestión.

E. H.: Cuando un director quiere hacer un espectáculo, lo primero que busca es un texto. Pues vamos a partir de ahí, vamos a partir de algo que hay que contar. Afortunadamente, los primeros que tienen algo que contar son los autores, entonces, vamos a ver qué dicen y qué quieren decir. Obviamente, unos pueden llegar a un público más amplio, otros a otro público menor pero igualmente respetable, que paga sus impuestos y forma parte de la población aunque sea minoritario. Entonces, sí, efectivamente, había que arrancar por los autores.

M.F. G.P.: Y ahora, viéndolo con distancia, ¿te parece que dio sus frutos? ¿Tuvo sentido todo aquello?

E. H.: Tuvo sentido. Los proyectos nunca dan los frutos que uno desea y espera que den, pero el hecho de que al cabo de los años "la Nueva Escuela Andaluza de Dramaturgia", o "la Nueva Dramaturgia Andaluza", como la llamaban los medios, invadiera Madrid y se hiciera con teatros y se empezara a representar por todas partes... ¡Hombre!, aquello que hicimos sí que ha merecido la pena. Realmente, allí había talento, y había que empujarlo. El merito es de quienes escriben, de quienes llegan al público, evidentemente; los demás lo que tenemos que hacer es ponerle el asfalto a las carreteras para que rueden.

M.F.G.P.: Tu paso por el CAT fue un impulso importante para la dramaturgia andaluza, pero cuando te marchaste, todo ese apoyo y ese interés por los nuevos autores se acabó. Las instituciones se olvidaron de nosotros.

E.H.: Bueno, yo confiaba en que el premio siguiera, en que las producciones siguieran, pero a partir del año 2004 en que yo acabé mi etapa, el compañero que tomó el relevo debió de tener muchos problemas con la administración, o económicos, a la hora de producir. El caso es que todo desapareció: el premio, la producción, la gira... Yo desconozco la razón, pero sé que hubo ahí un cambio de rumbo probablemente motivado por una radical reducción del presupuesto.

M.F.G.P.: ¿Y no te parece lamentable que la gestión del CAT esté supeditada a la persona que lo dirija y al momento económico en que se realice? Me da la impresión de que, como con tantas cosas en nuestro país, el que llega tiene siempre que partir de cero, y así una y otra vez, con lo que finalmente no se construye nada.

E.H.: En muchos casos así es, hay cosas que deberían pasar al dominio de la profesión. El CAT llenaba los teatro en Barcelona, y vendíamos representaciones de Bélgica a Suecia, en todos sitios. Producíamos con muy poco, y rentabilizamos nuestras producciones. Entre otras cosas, hacíamos giras de meses, con actores contratados fijos, que iban cambiando de una producción a otra, pues yo entendía que, al tratarse de un centro público, tenía que acoger a las personas con más potencial del teatro andaluz para apoyarlas y también para contribuir 
a su formación. Creamos una estructura estable, profesional, porque había demanda. Se creó una marca. Fue un modelo de gestión que funcionó, así que no entiendo por qué se dejó caer. Si hay un problema económico, hay que hacerle frente, hay que adaptarse... Hay cosas que la profesión tiene que defender como propias desde que se crean, cosas que no pueden depender del vaivén de las administraciones; sobre todo cuando algo se consolida después de siete años y da sus frutos. Porque, lo que no funciona, no tiene que prevalecer, pero cuando algo se demuestra que tiene sentido y además tiene una respuesta real del público como de los creadores, a partir de ahí lo normal es que los creadores negocien con el equipo de la administración para que aquello prevalezca, aunque haya que replantear presupuestos, aunque haya que recurrir al Estado. Así que tampoco entiendo por qué aquella batalla no se libró.

De todas formas, yo no desconfío, porque si hemos sido capaces de hacer importante la dramaturgia de esa generación [la "Romero Esteo"], que ha ido ocupando escenarios y escenarios por toda España, cómo no va a haber otra generación y otra y otra. Lo que hay es que estar ahí apoyando. Andalucía volverá a tener un Centro Andaluz de Teatro como el que ya tuvo, pero no creo que debamos dejarlo a iniciativa de las administraciones, ahí hay una responsabilidad de la profesión.

M. F. G. P.: Para terminar, ¿se te quedó algo en el tintero? ¿Hubo algo que hubieses querido realizar y no pudiste?

E. H.: Sí, claro. ¿Cómo no?. Cuando entré a dirigir el Festival de Almagro, volví a conectar con Andalucía para tratar de impulsar el teatro clásico andaluz. Desafortunadamente, no encontré respuesta en la administración andaluza. Quería apoyar el gran teatro clásico andaluz, algo tan importante como que es el segundo campo de teatro clásico del Estado: Madrid y Andalucía, el de Valencia es el tercero. Ahí hay un material increíble para que se reivindique la enorme importancia de Andalucía en el teatro renacentista y barroco.

Me sorprende mucho que no haya por parte de la administración la necesidad de aprovechar -no ya "aprovecharse", pero también- una efervescencia creativa como la andaluza. Porque oigo decir por todos lados: "Andalucía es tierra de arte”, de boquilla escucho muchas cosas, pero luego, ¿dónde están esos proyectos?.

Otra cosa importante, que se empezó a hacer, pero que no ha tenido continuación es la traducción de los textos de los nuevos autores andaluces. Hay que traducir. Yo hice mucho hincapié en que se tradujeran esos textos, al francés, al inglés... Había que darlos a conocer. Hay que insistir. Es una labor que está ahí, por hacerse, y yo entiendo que es posible, que es un deber de la administración pública, que no puede hacer caso omiso de eso, ni de otras cosas fundamentales. 